\title{
Association of placental pathology and postpartum cardiovascular risk screening following preeclampsia: an observational cohort study
}

\author{
Samantha Benton ${ }^{1}$, Erika Mery ${ }^{2}$, David Grynspan ${ }^{3}$, Laura Gaudet ${ }^{1}$, Graeme Smith $^{1}$, and \\ Shannon Bainbridge ${ }^{4}$ \\ ${ }^{1}$ Queen's University \\ ${ }^{2}$ University of Ottawa Faculty of Health Sciences \\ ${ }^{3}$ The University of British Columbia Faculty of Medicine \\ ${ }^{4}$ University of Ottawa
}

August 23, 2021

\begin{abstract}
Objective: To determine the association between placental lesions and lifetime cardiovascular disease (CVD) risk screening at 6 months postpartum following preeclampsia (PE). Design: Observational cohort study. Setting: Tertiary care centres in Ottawa and Kingston, Ontario, Canada. Population: Women diagnosed with PE who received cardiovascular screening at 6 months postpartum. Methods: Placentas from women diagnosed with PE were evaluated for histopathological lesions according to a standardised synoptic data collection form with blinding to clinical outcomes apart from gestational age at delivery. At 6 months postpartum, each participant was screened for cardiovascular risk factors and a lifetime cardiovascular risk score was calculated. A risk score $>35 \%$ was deemed high risk for lifetime CVD. Main Outcome Measures: The association between placental lesions and lifetime CVD risk was assessed using odds ratios (OR, 95\% confidence intervals). Results: Of the 85 participants, $53(62.4 \%)$ screened high-risk for lifetime CVD. High-risk women had more severe lesions of maternal vascular malperfusion (MVM). MVM lesions with a severity score $>2$ resulted in a 3-fold increased risk of screening high risk for lifetime CVD (OR 3.10 [1.20-7.92]). MVM lesion score >2 was moderately predictive of high-risk screening (AUC 0.63 [0.51,0.75]; sensitivity: $71.8 \%$ [54.6,84.4]; specificity: $54.7 \%[41.5,67.3])$. When clinical data was added, the model's predictive performance improved (AUC 0.73 [0.62,0.84] sensitivity 78.4\% [65.4,87.5]; specificity 51.6\% [34.8,68.0]). Conclusions: PE women with MVM are more likely to screen high-risk for lifetime CVD compared to women without these lesions. Placenta pathology may provide a unique modality to identify women for postpartum cardiovascular screening.
\end{abstract}

\section{Introduction}

Preeclampsia (PE) is a life-threatening hypertensive disorder of pregnancy, affecting 5-8\% of pregnancies worldwide. ${ }^{1}$ Importantly, PE is a significant risk indicator for cardiovascular disease (CVD) in later life. Women diagnosed with PE have a $\sim$-fold increased risk of hypertension and a ${ }^{\sim}$-fold increased risk of ischemic heart disease and stroke compared to women with uncomplicated pregnancies. ${ }^{2-5}$ Moreover, evidence suggests that women who develop severe PE during pregnancy are at highest risk of these outcomes. ${ }^{4,6-8}$ Alarmingly, studies show that onset of CVD and CVD-related death occur at much younger ages than the general female population. ${ }^{6-9}$ The link(s) between PE and cardiovascular risk are not fully understood but PE may indicate the presence of underlying, often undiagnosed, cardiovascular risk factors (CVRs). ${ }^{10,11}$ Moreover, underlying CVRs may directly contribute to placental dysfunction associated with PE, however this relationship has yet to be fully elucidated. ${ }^{12,13}$

Histopathological lesions of maternal vascular malperfusion (MVM) are commonly observed in placentas from PE pregnancies, particularly in cases of severe, early-onset disease. ${ }^{14-16}$ These lesions, including increased 
syncytial knots and accelerated villous maturation, are believed to reflect placental hypoxia and oxidative stress arising from incomplete uterine artery modelling and abnormal uteroplacental blood flow. ${ }^{1,17-18}$ Although common, MVM lesions are not observed in all PE cases and a proportion of PE placentas are histologically normal or exhibit other pathology such as chronic inflammation. ${ }^{19,20}$ Recent population-based studies have shown an association between placental lesions and future maternal health. ${ }^{21-25}$ Catov et al observed altered cardiometabolic profiles in women with preterm birth and lesions of MVM compared to women with term deliveries. ${ }^{21}$ Additionally, women with preterm birth and co-morbid placental pathologies (MVM, inflammatory lesions) had the most severe atherogenic profiles. ${ }^{21}$ Collectively, these studies provide strong evidence that the placenta and its pathology may provide a snapshot into future maternal cardiometabolic health. ${ }^{26}$

To reduce the burden of CVD on PE women, specialised postpartum cardiovascular health clinics are being established across North America to screen women for CVRs and initiate postpartum CVD prevention including pharmaceutical and lifestyle interventions. ${ }^{27-29}$ However, these clinics are resource intensive and thus, follow-up of all $\mathrm{PE}$ women is prohibitive. Moreover, a proportion of $\mathrm{PE}$ women will remain low risk for CVD postpartum and not require follow-up. As placental pathology is inexpensive and readily available, it may offer a unique modality to identify PE women for CVR screening. Here, we investigate the association between placental pathology and postpartum CVD risk in women following PE.

\section{Methods}

\section{Patient cohort}

In this study, a cohort of women diagnosed with $\mathrm{PE}$ who underwent cardiovascular health screening at 6 months postpartum was assembled from two study centres (Kingston and Ottawa, ON, Canada). In Kingston, women who develop a pregnancy complication are referred to the Maternal Health Clinic (Kingston General Hospital) for postpartum cardiovascular health screening at 6 months postpartum as part of routine, standard of care. Assessments and evaluations, including the calculation of a lifetime cardiovascular risk score, conducted at the Maternal Health Clinic have been previously described. ${ }^{28}$ From this clinic, we recruited eligible study participants at the time of their 6-month postpartum visit (between 2011 and 2017). Women diagnosed with $\mathrm{PE}$ who had placenta pathology performed at delivery of the index pregnancy (PE diagnosis) were approached to participate in the study.

In Ottawa, women were recruited to participate in the study as part of the DREAM Study research protocol designed to emulate the Maternal Health Clinic. Women diagnosed with PE prior to delivery were recruited from inpatient services at The Ottawa Hospital, General Campus between 2013 and 2018. Placentas from each participant were sent to Anatomical Pathology at the Children's Hospital of Eastern Ontario. Six months after delivery, participants returned to the Ottawa Hospital for cardiovascular health screening performed by the research study nurse. The assessments performed at this study visit were identical to those performed at the Maternal Health Clinic and a lifetime cardiovascular risk score was calculated for each participate as described previously. ${ }^{28}$ At both sites, all women provided written informed consent to participate in the study.

PE was defined according to the contemporaneous Society of Obstetricians and Gynaecologists of Canada criteria including hypertension (blood pressure [?]140/90 $\mathrm{mmHg}$, on at least two occasions > 15mins apart after 20 weeks' gestation) with new proteinuria ([?]0.3g/day by $24 \mathrm{~h}$ urine collection, [?]30 $\mathrm{mg} / \mathrm{mmol}$ by protein:creatinine ratio, or [?]1+ by urinary dipstick), or one or more adverse conditions (e.g., headache/visual symptoms, chest pain/dyspnea, nausea or vomiting, right upper quadrant pain, elevated WBC count) or one or more severe complications (e.g., eclampsia, uncontrolled severe hypertension, platelet count $<50 \times 10^{9} / \mathrm{L}$, acute kidney injury). ${ }^{30}$ Women with chronic hypertension, known CVD prior to pregnancy, known kidney disease prior to pregnancy, or diabetes (type I, type II, gestational) were excluded. Small-for-gestational age (SGA) status of the infant was determined if birthweight was $<5^{\text {th }}$ percentile for gestational age and sex. ${ }^{31}$ Clinical data including medical and family history, pregnancy outcome and postpartum cardiovascular health results were collected by chart review following 6 months postpartum cardiovascular screening. 


\section{Placenta tissue collection and histopathology}

For study participants in Ottawa, placentas were collected at the time of delivery and sent to Pathology. Trimmed placental weight was recorded and gross pathology was recorded by an experienced Pathology Assistant. Four full thickness tissue biopsies were randomly excised from each quadrant of the placenta, between the cord insertion site and the placental margins. Areas of visible pathology were sampled separately and not used for the full thickness sections. Tissue was fixed in $4 \%$ neutral buffered formalin and paraffin-embedded. Following sectioning $(5 \mathrm{um})$, tissue was stained with hematoxylin and eosin (H\&E) using standard protocol ${ }^{32}$ and stored for examination. In Kingston, archived H\&E-stained tissue slides (4-5 slides/participant) were accessed from Pathology archives for each participant. Sampling procedures were similar to those followed in Ottawa in that full thickness biopsies were excised from each quadrant of the placenta, between the margin and cord insertion site. Trimmed placenta weight and gross pathology were collected from accompanying placental pathology reports. A single, experience placental pathologist examined the stained slides from all study participants, blinded to all clinical information apart from gestational age at delivery. Placental lesions were evaluated according to a standardised placental pathology data collection form, with pre-specified severity criteria derived from clinical practice guidelines and published literature. ${ }^{33}$ Within the evaluation scheme, each lesion has a severity score to achieve a quantitative output for the severity of pathology. Lesions were either given a binary score of 0 (absent) or 1 (present) or a graded score according to a liner scale (i.e. $0=$ absent, 1 = focal, 2 = patchy, 3 = diffuse). Individual lesions are grouped according to broad etiological categories, with a maximum severity score calculated for each category. Lesion categories and maximum severity score for each category are as follows: MVM (max score 13), implantation site abnormalities (max score 4), histological chorioamnionitis (max score 11), placental villous maldevelopment (max score 5), fetal vascular malperfusion (max score 6), chronic utero-placental separation (max score 3), maternal-fetal interface disturbance (max score 5 ) and chronic inflammation (max score 6). Gross anatomy (e.g., placental weight, umbilical cord length) was obtained from the corresponding historical placental pathology reports, in addition to several microscopic lesions (e.g., placental infarction, chronic deciduitis), as the tissue biopsies were collected from areas that appeared grossly normal and only included villous parenchyma (i.e., maternal decidua was not sampled).

\section{Postpartum cardiovascular risk screening}

At 6 months postpartum, all women underwent physical and biochemical CVR screening in the Maternal Health Clinic (Kingston General Hospital) or at The Ottawa Hospital (Ottawa) according to published protocol. ${ }^{28} \mathrm{~A}$ full medical history was taken and included information on family history, breastfeeding and lifestyle such as smoking status and alcohol intake. A physical examination, specifically focusing on cardiovascular-related clinical predictors, was performed and collected information on weight, height, and blood pressure. A maternal blood sample was collected and total cholesterol, LDL cholesterol, HDL cholesterol, triglycerides, glucose and C-reactive protein were quantified for each participant. A random urine sample was collected and the albumin:creatinine ratio was measured. Physical and biochemical CVR findings were integrated to calculate a lifetime risk score for CVD, according to the previously published protocol. ${ }^{28}$ Calculations for lifetime cardiovascular risk are based on the following risk factors: total cholesterol, systolic blood pressure, diastolic blood pressure, use of antihypertensive medication(s), fasting blood glucose, diagnosis of diabetes and current smoking status. Risk stratification for each risk factor was based on predetermined measurement thresholds (optimal, not optimal, elevated, major). Lifetime cardiovascular risk estimates are also categorical and based on the total number of optimal, not optimal, elevated and major risk factors of each individual ( $8 \%$, all risk factors are optimal; $27 \%$, [?]1 risk factor is not optimal; $39 \%$, [?]1 risk factor is elevated; 39\%, 1 risk factor is major; $50 \%$, [?]2 risk factors are major). Lifetime cardiovascular risk estimates were simplified to categorize woman as low risk ( $<39 \%$ risk) or high risk ([?]39\% risk) for lifetime CVD. This threshold corresponds to the baseline lifetime CVD risk attributed to healthy women enrolled in the Framingham Heart Study. ${ }^{34}$

\section{Statistical analyses}

Data were analysed using SPSS 26.0 (SPSS Inc., Chicago, IL, USA). Descriptive data were expressed as 
means and standard deviations for normally distributed data or medians with interquartile ranges for nonnormally distributed data. Chi-square tests were used for comparison of categorical variables while Student's t-test or Mann-Whitney $U$ - tests were used for continuous variables.

Placental lesions (frequencies and severity scores) were compared between the low CVD risk and high CVD risk groups. The association between individual placental lesions and lifetime CVD risk was assessed using odds ratios (OR) with $95 \%$ confidence intervals. Multivariable logistic regression was used to develop prediction models for lifetime CVD risk with placental data alone or in combination with clinical data. Performance of the models were assessed using area under the receiver operator characteristic (AUC ROC) curve analysis.

\section{Results}

\section{Clinical characteristics}

A total of 85 women were included in this study (35 from Ottawa and 50 from Kingston). Clinical characteristics of the participants, as a combined cohort and by each study site, are shown in Table $\mathbf{1}$ and 2 . The demographic characteristics of the women between the two study sites were not significantly different, apart from maternal age and pre-pregnancy BMI. Although the average age of women in Kingston was 2 years younger than women in Ottawa $(\mathrm{p}=0.015)$, this difference is not deemed to be clinically significant. Although women in Ottawa had significantly higher pre-pregnancy BMIs than women in Kingston $(\mathrm{p}=0.024)$, the gestational weight gain for the index pregnancy was similar between the two sites $(13.2 \pm 7.1$ vs $14.6 \pm$ 7.1, $\mathrm{p}=0.393)$.

As for pregnancy outcomes, women in Kingston had significantly higher blood pressures at delivery, increased use of anti-hypertensive medication in pregnancy, delivered at earlier gestational ages compared to women in Ottawa $(34.0[31.0,38.0]$ weeks vs $37.5[34.4,39.4], \mathrm{p}<0.0001)$ and had more SGA infants compared with women in Ottawa. At 6 months postpartum, there were no significant differences in cardiometabolic parameters between the participants at the study sites. Of the 85 women included in the analysis, $53(62.4 \%)$ women screened high-risk for lifetime CVD at 6 months postpartum.

\section{Histopathology findings in low- and high-risk women}

The frequency of placenta lesions between women who screened low- and high-risk for lifetime CVD are shown in Table 3. A total of 5 placentas (15.6\%) in the low-risk group, and 6 placentas (11.3\%) in the high-risk group had no observed pathology $(\mathrm{p}=0.74)$. The mean cumulative severity score (sum of scores for all categories) for the low-risk group was $3.1 \pm 2.2$ and $3.6 \pm 2.4$ for the high-risk group $(\mathrm{p}=0.374)$. By etiological category, women who screened high-risk for lifetime CVD had placentas with more severe lesions of MVM (score [?]2: $54.7 \%$ vs $28.1 \%, \mathrm{p}=0.017$ ), however, the frequency of individual lesions belonging to the MVM category were not found to be significantly different between the groups.

\section{Association of placental lesions and CVD risk}

Individually, no placental lesions were found to be significantly associated with high-risk CVD screening at 6 months postpartum. However, PE women with lesions of MVM with a severity score of 2 or more were more likely to screen high-risk for lifetime CVD than PE women without severe MVM lesions (severity score $<2$ ) [OR 3.10 (1.20-7.92)]. Severity of MVM lesions (score 2 or more) was moderately predictive of high-risk screening at 6 months postpartum (AUC 0.63 (0.51, 0.75); sensitivity: $71.8 \%$ [54.6, 84.4]; specificity: $54.7 \%$ $[41.5,67.3]$ ) (Figure 1). When clinical data (maternal age, gestational weight gain, blood pressure at delivery, gestational age at delivery) was added, the model's predictive performance improved marginally (AUC $0.73(0.62,0.84)$ sensitivity $78.4 \%[65.4,87.5]$; specificity 51.6\% [34.8, 68.0]) (Figure 1) .

\section{Discussion}

\section{Main Findings}

In this study, we observed an increase in placental histopathological lesions in women who screened high 
risk for lifetime CVD at 6 months postpartum following a PE pregnancy. Specifically, high-risk women had more severe lesions of MVM, the placental pathology traditionally associated with PE. MVM lesions with a severity score $>2$ or more resulted in a 3 -fold increased risk of screening high risk for lifetime CVD at 6 months postpartum. The cumulative severity of MVM lesions was important in this association, suggesting that there may be critical thresholds of placental damage that reflect increased lifetime cardiovascular risk.

\section{Interpretation}

Previous studies have demonstrated an association between placental pathology and increased postpartum maternal cardiovascular health risk. ${ }^{21-25}$ One study found that in normotensive women who experienced placental abruption during pregnancy, CVRs were significantly altered 6-9 months postpartum compared to women without uncomplicated pregnancies. ${ }^{25}$ Lesions of maternal vascular maldevelopment (defined as mural hyperplasia, unaltered decidual vessels and decidual atherosis) are associated with maternal hypertension 7 to 15 years after pregnancy. ${ }^{35}$ Catov et al. reported that in normotensive women who delivered preterm without fetal growth restriction, those who had placental lesions of MVM and inflammation had significantly elevated atherogenic profiles assessed 4-12 years after delivery. ${ }^{21}$ Our findings are line with this study in which the cumulative severity of placental lesions may be important for identifying women at highest cardiovascular risk following pregnancy. Together with our current findings, significant placental pathology may be indicative of greater risk for CVD postpartum.

The mechanisms linking PE and postpartum maternal cardiovascular risk have yet to be fully elucidated. The most commonly held hypothesis to explain this link proposes that pre-pregnancy maternal CVRs including both clinically-diagnosed and subclinical risk factors, may contribute to the development of PE, including abnormal placental development, and predispose women to CVD after pregnancy. Placentation requires the invasion of fetal trophoblast cells into the maternal decidua, resulting in conversion of the maternal uterine spiral arteries to high capacity, venous-like conduits to increase blood flow into the uteroplacental unit to support fetal growth and development. ${ }^{36}$ This physiological remodeling of the uterine spiral arteries is known to be defective in PE and the two-stage model of pathogenesis proposes that this failed remodeling leads to placental ischemia, oxidative stress and placental dysfunction which stimulates the release of angiogenic factors, pro-inflammatory cytokines, syncytiotrophoblast vesicles and other factors from the placenta. ${ }^{1}$ These processes result in characteristic histopathological lesions observed in placentas from pregnancies complicated by PE, particularly lesions of MVM. ${ }^{37}$ Placenta-derived circulating factors interact with the maternal endothelium at the systemic level, leading to the end-organ dysfunction observed in the clinical manifestation of the disorder. The maternal environment, including subclinical CVRs common to $\mathrm{PE}$ and CVD, may directly contribute to impaired trophoblast invasion and defective spiral artery conversion and its downstream effects. Dyslipidemia including elevated pre-pregnancy levels of serum triglycerides, cholesterol, LDL and non-HDL cholesterol have been associated with increased risk of developing PE and are known contributors to CVD. ${ }^{38}$ Studies have shown that lipids modulate human trophoblast invasion and alterations in maternal lipid profiles could potentially contribute to abnormal trophoblast invasion and spiral artery remodelling. ${ }^{39,40}$ Systemic (often subclinical) inflammation, common in obesity and other cardiometabolic conditions, may also play a role in limited trophoblast invasion and spiral artery conversion during placentation in PE. ${ }^{41,42}$ Pro-inflammatory cytokines are known to inhibit trophoblast invasion by increasing apoptosis and decreasing proliferation. ${ }^{43}$ Cytokine imbalance prior to pregnancy may alter the maternal inflammatory milieu over and above the physiological immune/inflammatory changes that occur in pregnancy, however, exactly how this imbalance contributes to altered placentation is unknown.

PE and placental dysfunction, reflected as MVM lesions in the placenta, may also cause lasting damage to the maternal cardiovascular system that results in altered cardiovascular health trajectories. Circulating levels of inflammatory cytokines such as tumor necrosis factor-a (TNF-a) and interleukin-6 (IL-6) are elevated in PE and interfere with the maternal endothelium to produce systemic endothelial dysfunction. Women diagnosed with PE have been found to have chronically altered circulating levels of these cytokines $>20$ years after pregnancy suggesting that PE may program the maternal cardiovasculature such that there is persistent cardiovascular dysregulation and precipitating CVD in later life. ${ }^{44}$ Anti-angiogenic imbalance 
in the maternal circulation, including elevated soluble Fms-like tyrosine kinase-1 (sFlt-1) and reduced placental growth factor (PlGF), may contribute to lasting cardiovascular dysfunction after PE. Alternations in circulating angiogenic factors during pregnancy are associated with cardiovascular changes including increased blood pressure 6 to 12 years after pregnancy. ${ }^{45,46}$ Although angiogenic factors levels significantly drop following delivery, a recent study suggests that angiogenic imbalance may persistent in the postpartum period. ${ }^{47}$ While the mechanisms of angiogenic factors on cardiovascular health are not fully known, sFlt-1 and PlGF have been shown to influence vasodilatory function in preclinical models. ${ }^{48,49}$

It is plausible that a combination of the pre-pregnancy maternal environment and persistent alterations to the maternal cardiovascular system from placental dysfunction contribute to future CVD risk. Placental pathology, particularly lesions of MVM, may reflect both abnormalities in the maternal milieu as well as the significant cardiovascular burden from abnormal placentation, thereby identifying patients at particularly increased risk of postpartum CVD. As such, placental lesions identified at the time of delivery, could provide a modality to triage PE women for cardiovascular health screening postpartum. Future studies are required to confirm the utility of placental pathology in this capacity, but it may offer a unique opportunity to extend the clinical benefits of the placenta pathology exam while targeting postpartum resource-intensive cardiovascular screening to the most vulnerable patients.

\section{Strengths and limitations}

Limitations of our study need to be considered. First, inclusion of participants from our Kingston cohort required retrospective analysis of placentas that were originally submitted to Pathology for examination. This aspect of the study design may have resulted in selection bias, as although PE is an indication for pathology examination, not all placentas are sent. ${ }^{50}$ We did observe a significant difference in several important pregnancy parameters between our study sites, including blood pressure at delivery, anti-hypertensive use at delivery and gestational age at delivery. These differences may be due to placenta pathology referral practices, as it is likely that placentas from women with more severe PE disease are more frequently selected for submission to pathology (and thus available for inclusion in our study). As cardiovascular parameters were similar between our cohorts at the 6 month postpartum clinic visit, we do not feel these delivery parameters influenced our findings. Due to our small sample size, we may be underpowered to detect differences between low and high-risk groups for less common pathology, such as chronic inflammation. Confirming our results in an adequately powered prospective study may identify a predictive combination of placental lesions that robustly identifies high priority women for postpartum CVD screening at the time of delivery. Our study is strengthened by the standardised placental evaluations we conducted using our evidence-based synoptic data collection. ${ }^{33}$ Variability in placenta pathology examination is a known challenge and the use of this synoptic collection form ensures each placenta was evaluated in a reproducible manner.

\section{Conclusions}

Women with PE and severe lesions of MVM are more likely to screen high-risk for lifetime CVD at 6 months postpartum compared to women without these lesions. Placenta pathology may provide a unique modality to identify women for postpartum cardiovascular screening.

\section{Disclosure of interests}

The authors declare they have no actual or potential com-

peting financial interests. Completed disclosure of interest

forms are available to view online as supporting informa-

tion.

The authors declare they have no actual or potential com-

peting financial interests. Completed disclosure of interest

forms are available to view online as supporting informa- 
tion.

The authors declare they have no actual or potential competing financial interests. Completed disclosure of interest forms are available to view online as supporting information.

\section{Contribution to authorship}

TM and SM designed the study and developed the analysis

plan. TM collected and analysed the data, and wrote the

manuscript. SM and KK collected data and interpreted the

data. SY, HN, and YN carried out the literature search, and

supported the analysis. AS measured Asian dust, and inter-

preted the data. All authors reviewed the manuscript and

gave final approval for the manuscript.

SAB, SJB and GNS designed the study and developed the analysis plan. SJB, DG and GNS collected the clinical data. SAB, SJB, LG, GNS and DG carried out the clinical and biological interpretation of the data collected. SJB and EM carried out the detailed data analysis and manuscript preparation. All authors reviewed, provided edits and gave final approval for the manuscript.

\section{Details of ethics approval}

Ethics approval was granted by the Research Ethics Boards of the Ottawa Health Science Network (2014079901H; April 22, 2015), the Children's Hospital of Eastern Ontario (14/210X; March 23, 2015), the University of Ottawa (A04-15-01; April 1, 2014) and Queen's University Health Science and Affiliated Teaching Hospitals Research Ethics Board (OBGY-295-16; Jan 13, 2017).

\section{Funding}

This study was supported in part by a Canadian Institutes of Health Research (CIHR) operating grant (Grant number 130548; SA Bainbridge) and an innovation grant from The Ottawa Hospital Academic Medical Organization (TOHAMO; S A Bainbridge, D Grynspan, L Gaudet). SJ Benton is supported by a Molly Towell Research Fellowship and a CIHR Postdoctoral Fellowship; EE Mery is supported by a CIHR Graduate Scholarship. These competitive funding sources were peer-reviewed. None of the funding sources had any role in the design, collection, analysis, and interpretation of the data; the writing of the report; or the decision to submit the article for publication.

\section{Acknowledgments}

The authors thank the staff and patients at the Maternal Health Clinic at Kingston General Hospital for their participation in this study, particularly Ms. Jessica Pudwell for her help in extracting clinical chart data and helping with identification of archived placental samples. Likewise, the authors would like to thank the

staff and patients that participated in the DREAM study at The Ottawa Hospital. Special thanks to Alysha Harvey and members of Obstetrics and Maternal Newborn Investigations (OMNI, The Ottawa Hospital) for their help in coordination of patient recruitment and extraction of clinical chart data for the DREAM study participants.

\section{Table/Figure Caption List}

Table 1. Maternal characteristics of the study participants as a combined cohort and by individual study site. Presented as mean +- SD, median $[\mathrm{IQR}]$ or $\mathrm{n}(\%)$.

Table 2. Delivery and postpartum characteristics of the study participants as a combined cohort and by individual study site.Presented as mean +- SD, median [IQR] or n (\%). 
Table 3. Frequency of placental lesions by cardiovascular risk group. Presented as n (\%).

Figure 1. Area under the receiver operator characteristic curves for the prediction of screening high-risk for lifetime cardiovascular disease at 6 months postpartum by (a) maternal vascular malperfusion severity score and (b) maternal vascular malperfusion severity score, maternal age, gestational weight gain, blood pressure at delivery and gestational age at delivery. Maternal vascular malperfusion severity score $>2$ had an area under the curve of $0.63(0.51,0.75)$ for predicting high-risk screening at 6 months postpartum. Maternal vascular malperfusion score $>2$ with maternal age, gestational weight gain, blood pressure at delivery, gestational age at delivery had an area under the curve of $0.73(0.62,0.84)$.

\section{References}

1. Steegers EAP, von Dadelszen P, Duvekot JJ, Pijnenborg R. Pre-eclampsia. Lancet. 2010 Aug;376(9741):631-44.

2. Bellamy L, Casas JP, Hingorani AD, Williams DJ. Pre-eclampsia and risk of cardiovascular disease and cancer in later life: Systematic review and meta-analysis. Br J Med. 2007 Nov;335(7627):974

3. Okoth K, Chandan JS, Marshall T, Thangaratinam S, Thomas GN, Nirantharakumar K, et al. Association between the reproductive health of young women and cardiovascular disease in later life: umbrella review. BMJ. 2020 Oct;371:m3502.

4. Brown MC, Best KE, Pearce MS, Waugh J, Robson SC, Bell R. Cardiovascular disease risk in women with pre-eclampsia: systematic review and meta-analysis. Eur J Epidemiol. 2013 Jan;28(1):1-19.

5. Smith GN, Pudwell J, Walker M, Wen S-W. Ten-year, thirty-year, and lifetime cardiovascular disease risk estimates following a pregnancy complicated by preeclampsia. J Obstet Gynaecol Can. 2012 Sep;34(9):830-5.

6. McDonald SD, Malinowski A, Zhou Q, Yusuf S, Devereaux PJ. Cardiovascular sequelae of preeclampsia/eclampsia: a systematic review and meta-analyses. Am Heart J. 2008 Nov;156(5):918-30.

7. Mongraw-Chaffin ML, Cirillo PM, Cohn BA. Preeclampsia and cardiovascular disease death: prospective evidence from the child health and development studies cohort. Hypertension. 2010 Jul;56(1):16671.

8. Ray JG, Vermeulen MJ, Schull MJ, Redelmeier DA. Cardiovascular health after maternal placental syndromes (CHAMPS): population-based retrospective cohort study. Lancet. 2005 Nov;366(9499):1797803.

9. Smith GC, Pell JP, Walsh D. Pregnancy complications and maternal risk of ischaemic heart disease: a retrospective cohort study of 129,290 births. Lancet. 2001 Jun;357(9273):2002-6.

10. Smith GN, Walker MC, Liu A, Wen SW, Swansburg M, Ramshaw H, et al. A history of preeclampsia identifies women who have underlying cardiovascular risk factors. Am J Obstet Gynecol. 2009 Jan;200(1):58.e1-8.

11. Heidema WM, Scholten RR, Lotgering FK, Spaanderman MEA. History of preeclampsia is more predictive of cardiometabolic and cardiovascular risk factors than obesity. Eur J Obstet Gynecol Reprod Biol. 2015 Nov; 194:189-93.

12. Yinon Y, Kingdom JCP, Odutayo A, Moineddin R, Drewlo S, Lai V, et al. Vascular dysfunction in women with a history of preeclampsia and intrauterine growth restriction: insights into future vascular risk. Circulation. 2010 Nov;122(18):1846-53.

13. Kvehaugen AS, Dechend R, Ramstad HB, Troisi R, Fugelseth D, Staff AC. Endothelial function and circulating biomarkers are disturbed in women and children after preeclampsia. Hypertension. 2011 Jul;58(1):63-9.

14. Fillion A, Guerby P, Menzies D, Lachance C, Comeau M-P, Bussieres M-C, et al. Pathological investigation of placentas in preeclampsia (the PEARL study). Hypertens Pregnancy. 2021 Feb;40(1):56-62.

15. Weiner E, Feldstein O, Tamayev L, Grinstein E, Barber E, Bar J, et al. Placental histopathological lesions in correlation with neonatal outcome in preeclampsia with and without severe features. Pregnancy Hypertens. 2018 Apr;12:6-10.

16. Kovo M, Schreiber L, Ben-Haroush A, Gold E, Golan A, Bar J. The placental component in early-onset 
and late-onset preeclampsia in relation to fetal growth restriction. Prenat Diagn. 2012 Jul;32(7):632-7.

17. Burton GJ, Redman CW, Roberts JM, Moffett A. Pre-eclampsia: pathophysiology and clinical implications. BMJ. 2019 Jul;366:12381.

18. Schneider H. Placental dysfunction as a key element in the pathogenesis of preeclampsia. Dev Period Med. 2017;21(4):309-16.

19. Benton SJ, Leavey K, Grynspan D, Cox BJ, Bainbridge SA. The clinical heterogeneity of preeclampsia is related to both placental gene expression and placental histopathology. Am J Obstet Gynecol. 2018 Dec;219(6): 604.e1-604.e25.

20. Falco ML, Sivanathan J, Laoreti A, Thilaganathan B, Khalil A. Placental histopathology associated with pre-eclampsia: systematic review and meta-analysis. Ultrasound Obstet Gynecol. 2017 Sep;50(3):295-301.

21. Catov JM, Muldoon MF, Reis SE, Ness RB, Nguyen LN, Yamal J-M, et al. Preterm birth with placental evidence of malperfusion is associated with cardiovascular risk factors after pregnancy: a prospective cohort study. BJOG. 2018 Jul;125(8):1009-17.

22. Brosens I, Benagiano M, Puttemans P, D'Elios MM, Benagiano G. The placental bed vascular pathology revisited: a risk indicator for cardiovascular disease. J Matern Fetal Neonatal Med. 2019 May;32(9):1556-64.

23. Stevens DU, Smits MP, Bulten J, Spaanderman MEA, van Vugt JMG, Al-Nasiry S. Prevalence of hypertensive disorders in women after preeclamptic pregnancy associated with decidual vasculopathy. Hypertens pregnancy. 2015;34(3):332-41.

24. Stevens DU, Al-Nasiry S, Fajta MM, Bulten J, van Dijk AP, van der Vlugt MJ, et al. Cardiovascular and thrombogenic risk of decidual vasculopathy in preeclampsia. Am J Obstet Gynecol. 2014 Jun;210(6):545.e1-6.

25. Veerbeek JHW, Smit JG, Koster MPH, Post Uiterweer ED, van Rijn BB, Koenen S V, et al. Maternal cardiovascular risk profile after placental abruption. Hypertension. 2013 Jun;61(6):1297-301.

26. Parks WT, Catov JM. The placenta as a window to maternal vascular health. Obstet Gynecol Clin North Am. 2020 Mar;47(1):17-28.

27. Park K, Minissian MB, Wei J, Saade GR, Smith GN. Contemporary clinical updates on the prevention of future cardiovascular disease in women who experience adverse pregnancy outcomes. Clin Cardiol. 2020 Jun;43(6):553-9.

28. Cusimano MC, Pudwell J, Roddy M, Cho C-KJ, Smith GN. The maternal health clinic: an initiative for cardiovascular risk identification in women with pregnancy-related complications. Am J Obstet Gynecol. 2014;210(5):438.e1-438.e9.

29. Smith GN. The Maternal Health Clinic: Improving women's cardiovascular health. Semin Perinatol. 2015 Jun;39(4):316-9.

30. Magee LA, Pels A, Helewa M, Rey E, von Dadelszen P. Canadian Hypertensive Disorders of Pregnancy Working Group. Diagnosis, evaluation, and management of the hypertensive disorders of pregnancy: executive summary. J Obstet Gynaecol Can. 2014 May;36(5):416-41.

31. Kramer MS, Platt RW, Wen SW, Joseph KS, Allen A, Abrahamowicz M, et al. A new and improved population-based Canadian reference for birth weight for gestational age. Pediatrics. 2001 Aug;108(2):E35.

32. Warrander LK, Batra G, Bernatavicius G, Greenwood SL, Dutton P, Jones RL, Sibley CP, Heazell AE. Maternal perception of reduced fetal movements is associated with altered placental structure and function. PLoS One. 2012;7(4):e34851.

33. Benton SJ, Lafreniere AJ, Grynspan D, Bainbridge SA. A synoptic framework and future directions for placental pathology reporting. Placenta. 2019 Feb;77:46-57.

34. Lloyd-Jones DM, Leip EP, Larson MG, D'Agostino RB, Beiser A, Wilson PWF, et al. Prediction of lifetime risk for cardiovascular disease by risk factor burden at 50 years of age. Circulation. 2006 Feb;113(6):791-8.

35. Holzman CB, Senagore P, Xu J, Dunietz GL, Strutz KL, Tian Y, et al. Maternal risk of hypertension 7-15 years after pregnancy: clues from the placenta. BJOG. 2021 Apr;128(5):827-36. 
36. Pijnenborg R, Vercruysse L, Hanssens M. The uterine spiral arteries in human pregnancy: facts and controversies. Placenta. 2006;27(9-10):939-58.

37. Bustamante Helfrich B, Chilukuri N, He H, Cerda SR, Hong X, Wang G, et al. Maternal vascular malperfusion of the placental bed associated with hypertensive disorders in the Boston Birth Cohort. Placenta. 2017 Apr; 52:106-13.

38. Magnussen EB, Vatten LJ, Lund-Nilsen TI, Salvesen KA, Davey Smith G, Romundstad PR. Prepregnancy cardiovascular risk factors as predictors of pre-eclampsia: population-based cohort study. BMJ. 2007 Nov;335(7627):978.

39. Pavan L, Tsatsaris V, Hermouet A, Therond P, Evain-Brion D, Fournier T. Oxidized low-density lipoproteins inhibit trophoblastic cell invasion. J Clin Endocrinol Metab. 2004 Apr;89(4):1969-72.

40. Pavan L, Hermouet A, Tsatsaris V, Therond P, Sawamura T, Evain-Brion D, et al. Lipids from oxidized low-density lipoprotein modulate human trophoblast invasion: involvement of nuclear liver X receptors. Endocrinology. 2004 Oct;145(10):4583-91.

41. Wolf M, Kettyle E, Sandler L, Ecker JL, Roberts J, Thadhani R. Obesity and preeclampsia: the potential role of inflammation. Obstet Gynecol. 2001 Nov;98(5 Pt 1):757-62.

42. Bodnar LM, Ness RB, Harger GF, Roberts JM. Inflammation and triglycerides partially mediate the effect of prepregnancy body mass index on the risk of preeclampsia. Am J Epidemiol. 2005 Dec;162(12):1198-206.

43. Otun HA, Lash GE, Innes BA, Bulmer JN, Naruse K, Hannon T, et al. Effect of tumour necrosis factor- $\alpha$ in combination with interferon- $\gamma$ on first trimester extravillous trophoblast invasion. J Reprod Immunol. 2011 Jan;88(1):1-11.

44. Freeman DJ, McManus F, Brown EA, Cherry L, Norrie J, Ramsay JE, et al. Short- and longterm changes in plasma inflammatory markers associated with preeclampsia. Hypertension. 2004 Nov;44(5):708-14.

45. Garrido-Gimenez C, Mendoza M, Cruz-Lemini M, Galian-Gay L, Sanchez-Garcia O, Granato C, et al. Angiogenic factors and long-term cardiovascular risk in women that developed preeclampsia during pregnancy. Hypertension. 2020 Dec;76(6):1808-16.

46. Benschop L, Schalekamp-Timmermans S, Broere-Brown ZA, Roeters van Lennep JE, Jaddoe VW V, Roos-Hesselink JW, et al. Placental growth factor as an indicator of maternal cardiovascular risk after pregnancy. Circulation. 2019 Apr;139(14):1698-709.

47. Akhter T, Wikström A-K, Larsson M, Larsson A, Wikström G, Naessen T. Association between angiogenic factors and signs of arterial aging in women with pre-eclampsia. Ultrasound Obstet Gynecol. 2017 Jul;50(1):93-9.

48. Osol G, Celia G, Gokina N, Barron C, Chien E, Mandala M, Luksha L, Kublickiene K. Placental growth factor is a potent vasodilator of rat and human resistance arteries. Am J Physiol Heart Circ Physiol. 2008 Mar;294(3):H1381-7.

49. Amraoui F, Spijkers L, Hassani Lahsinoui H, Vogt L, van der Post J, Peters S, Afink G, Ris-Stalpers C, van den Born BJ. SFlt-1 elevates blood pressure by augmenting endothelin-1-mediated vasoconstriction in mice. PLoS One. 2014 Mar 14;9(3):e91897.

50. Sills A, Steigman C, Ounpraseuth ST, Odibo I, Sandlin AT, Magann EF. Pathologic examination of the placenta: recommended versus observed practice in a university hospital. Int J Womens Health. 2013 Jun 12;5:309-12.

Table 1. Maternal characteristics of the study participants as a combined cohort and by individual study site. Presented as mean $\pm \mathrm{SD}$, median $[\mathrm{IQR}]$ or $\mathrm{n}(\%)$.

\begin{tabular}{|c|c|c|c|c|}
\hline & $\begin{array}{l}\text { Combined } \\
(\mathrm{n}=85)\end{array}$ & Ottawa $(n=35)$ & $\begin{array}{l}\text { Kingston }(n= \\
50)\end{array}$ & $\begin{array}{l}P \text {-value }{ }^{\S}(\text { T-test, } \\
\left.\mathrm{KW}, X^{2}\right)\end{array}$ \\
\hline Maternal & Maternal & Maternal & Maternal & Maternal \\
\hline Characteristics & Characteristics & Characteristics & Characteristics & Characteristics \\
\hline $\begin{array}{l}\text { Maternal age at } \\
\text { delivery }(y)\end{array}$ & $31.9 \pm 6.0$ & $33.9 \pm 5.6$ & $30.7 \pm 5.9$ & 0.015 \\
\hline
\end{tabular}




\begin{tabular}{|c|c|c|c|c|}
\hline & $\begin{array}{l}\text { Combined } \\
(\mathrm{n}=85)\end{array}$ & Ottawa $(\mathrm{n}=35)$ & $\begin{array}{l}\text { Kingston }(n= \\
50)\end{array}$ & $\begin{array}{l}P \text {-value } \text { - }^{\text {(T-test }} \\
\left.\mathrm{KW}, X^{2}\right)\end{array}$ \\
\hline $\begin{array}{l}\text { Postsecondary } \\
\text { education }(\%)\end{array}$ & $74(88.1)^{\mathrm{a}}$ & $31(91.2)^{\mathrm{a}}$ & $43(86.0)$ & 0.520 \\
\hline $\begin{array}{l}\text { Married or } \\
\text { common law }\end{array}$ & $80(95.2)^{\mathrm{a}}$ & $35(100)$ & $45(91.8)^{\mathrm{a}}$ & 0.137 \\
\hline Nulliparous (\%) & $59(69.4)$ & $22(62.9)$ & $37(74.0)$ & 0.341 \\
\hline $\begin{array}{l}\text { Pre-pregnancy } \\
\text { BMI }\end{array}$ & $24.5[22.1,31.0]$ & $28.2[23.0,35.5]$ & $24.4[21.9,28.5]$ & 0.024 \\
\hline Smoking (\%) & $6(7.1)$ & $1(2.9)$ & $5(10.0)$ & 0.393 \\
\hline $\begin{array}{l}\text { Previous history } \\
\text { of HDPs }(\%)\end{array}$ & $11(12.9)$ & $7(20.0)$ & $4(8.0)$ & 0.187 \\
\hline $\begin{array}{l}\text { Family history of } \\
\left.\text { CVD* }^{*} \%\right)\end{array}$ & $44(52.4)^{\mathrm{a}}$ & $16(47.1)^{\mathrm{a}}$ & $28(56.0)$ & 0.506 \\
\hline $\begin{array}{l}\text { Family history of } \\
\mathrm{PE}(\%)\end{array}$ & $12(15.0)(\mathrm{n}=80)$ & $6(20.0)(\mathrm{n}=30)$ & $6(12.0)$ & 0.520 \\
\hline
\end{tabular}

BMI: body mass index; CVD: cardiovascular disease; HDP: hypertensive disorders of pregnancy; IQR: interquartile range; PE: preeclampsia; SD: standard deviation

$\S$ Comparison between participants in Ottawa and Kingston

*Includes coronary artery disease and cerebral vascular disease

${ }^{a}$ Data missing for one participant

Table 2. Delivery and postpartum characteristics of the study participants as a combined cohort and by individual study site.Presented as mean $\pm \mathrm{SD}$, median [IQR] or $\mathrm{n}(\%)$.

\begin{tabular}{llll}
\hline & Combined $(\mathbf{n}=\mathbf{8 5})$ & Ottawa $(\mathbf{n}=\mathbf{3 5})$ & Kingston $(\mathbf{n}=\mathbf{5}$ \\
\hline At delivery & At delivery & At delivery & At delivery \\
Systolic BP*(mmHg) & $152 \pm 25$ & $136 \pm 17$ & $164 \pm 22$ \\
Diastolic BP*(mmHg) & $93 \pm 13$ & $85 \pm 10$ & $98 \pm 13$ \\
Antihypertensive medication** $(\%)$ & $38(44.7)$ & $28(80.0)$ & $6(12.0)$ \\
Pregnancy weight gain $(\mathrm{kg})$ & $14.0 \pm 7.1$ & $13.2 \pm 7.1$ & $14.6 \pm 7.1$ \\
Gestational age delivery & $36.0[32.2,38.0]$ & $37.5[34.4,39.4]$ & $34.0[31.0,38.0]$ \\
Delivery before 37 weeks gestation (\%) & $48(56.5)$ & $11(31.4)$ & $37(74.0)$ \\
Cesarean section (\%) & $44(51.8)$ & $14(40.0)$ & $30(60.0)$ \\
Female infant (\%) & $42(49.4)$ & $13(37.1)$ & $29(58.0)$ \\
Birthweight (g) & $2200[1495,3098]$ & $2655[2075,3280]$ & $1920[1285,2351]$ \\
Small for gestational age $\left(<5^{\text {th }}\right.$ percentile) & $15(17.6)$ & $5(14.3)$ & $10(20.0)$ \\
Admission to NICU (\%) & $59(69.4)$ & $15(42.9)$ & $44(88.0)$ \\
Placental weight (g) & $334[274,443]$ & $382[326,516]$ & $312[236,431$ \\
At 6months postpartum & At 6months postpartum & $\mathbf{A t ~ 6 m o n t h s ~ p o s t p a r t u m ~}$ & $\mathbf{A t ~ 6 m o n t h s ~ p o s}$ \\
Systolic BP (mmHg) & $119 \pm 18$ & $116 \pm 23$ & $121 \pm 13$ \\
Diastolic BP (mmHg) & $81 \pm 10$ & $78 \pm 9$ & $82 \pm 10$ \\
Antihypertensive medication use $(\%)$ & $13(15.3)$ & $5(14.3)$ & $8(16.0)$ \\
Breastfeeding (\%) & $44(52.4)$ & $22(64.7)$ & $22(44.0)$ \\
Total cholesterol & $4.8 \pm 1.0$ & $4.9 \pm 1.0$ & $4.7 \pm 1.0$ \\
Fasting glucose & $4.8 \pm 0.5$ & $4.7 \pm 0.5$ & $4.8 \pm 0.5$ \\
HDL & $1.5 \pm 0.4$ & $1.5 \pm 0.4$ & $1.5 \pm 0.4$
\end{tabular}




\begin{tabular}{llll}
\hline & Combined $(\mathbf{n}=\mathbf{8 5})$ & Ottawa $(\mathbf{n}=\mathbf{3 5})$ & Kingston $(\mathbf{n}=5$ \\
\hline LDL & $2.8[2.2,3.4]$ & $3.0[2.2,3.5]$ & $2.6[2.1,3.3]$ \\
CRP & $2.6[1.0,7.4]$ & $2.6[0.9,8.4]$ & $2.0[0.98,5.9]$ \\
Triglycerides & $0.98[0.67,1.69]$ & $0.98[0.72,1.88]$ & $0.96[0.65,1.60]$ \\
Screen high-risk for lifetime CVD $(\%)$ & $53(62.4)$ & $18(51.4)$ & $35(70.0)$ \\
\hline
\end{tabular}

BP: blood pressure; CRP: C-reactive protein; CVD: cardiovascular disease; HDL: high density lipoprotein; IQR: interquartile range; LDL: low density lipoprotein; NICU: neonatal intensive care unit; PE: preeclampsia; SD: standard deviation

$\S$ Comparison between participants in Ottawa and Kingston

* Highest BP measurement following admission before delivery

**Medication started during index pregnancy or postpartum prior to discharge from hospital

Table 3. Frequency of placental lesions by cardiovascular risk group. Presented as n (\%).

\begin{tabular}{|c|c|c|c|}
\hline Placental Lesion & $\begin{array}{l}\text { High CVD Risk ( } \mathrm{n}= \\
\text { 53) }\end{array}$ & $\begin{array}{l}\text { Low CVD Risk }(\mathrm{n}= \\
\text { 32) }\end{array}$ & $P$-value (Pearson $\boldsymbol{X}^{2}$ ) \\
\hline $\begin{array}{l}\text { Evidence of } \\
\text { maternal vascular } \\
\text { malperfusion }\end{array}$ & $\begin{array}{l}\text { Evidence of } \\
\text { maternal vascular } \\
\text { malperfusion }\end{array}$ & $\begin{array}{l}\text { Evidence of } \\
\text { maternal vascular } \\
\text { malperfusion }\end{array}$ & $\begin{array}{l}\text { Evidence of } \\
\text { maternal vascular } \\
\text { malperfusion }\end{array}$ \\
\hline Placental infarction & $16(30.2)$ & $7(21.9)$ & 0.403 \\
\hline $\begin{array}{l}\text { Distal villous } \\
\text { hypoplasia }\end{array}$ & $15(28.3)$ & $8(25.0)$ & 0.740 \\
\hline $\begin{array}{l}\text { Accelerated villous } \\
\text { maturation }\end{array}$ & $31(58.5)$ & $12(37.5)$ & 0.061 \\
\hline Syncytial knots & $34(64.2)$ & $17(53.1)$ & 0.315 \\
\hline $\begin{array}{l}\text { Perivillous fibrin } \\
\text { deposition }\end{array}$ & $5(9.4)$ & $6(18.8)$ & 0.215 \\
\hline Villous agglutination & $7(13.2)$ & $1(3.1)$ & 0.123 \\
\hline MVM Score 1 or less & $8(15.1)$ & $9(28.1)$ & 0.146 \\
\hline MVM Score 2 or more & $29(54.7)$ & $9(28.1)$ & 0.017 \\
\hline $\begin{array}{l}\text { Evidence of } \\
\text { maternal decidual } \\
\text { arteriopathy }\end{array}$ & $\begin{array}{l}\text { Evidence of } \\
\text { maternal decidual } \\
\text { arteriopathy }\end{array}$ & $\begin{array}{l}\text { Evidence of } \\
\text { maternal decidual } \\
\text { arteriopathy }\end{array}$ & $\begin{array}{l}\text { Evidence of } \\
\text { maternal decidual } \\
\text { arteriopathy }\end{array}$ \\
\hline $\begin{array}{l}\text { Insufficient vessel } \\
\text { remodeling }\end{array}$ & $7(13.2)$ & $2(6.3)$ & 0.312 \\
\hline Fibrinoid necrosis & $4(7.5)$ & $2(6.3)$ & 0.821 \\
\hline $\begin{array}{l}\text { Decidual arteriopathy } \\
\text { present }\end{array}$ & $9(17.0)$ & $3(10.3)$ & 0.416 \\
\hline $\begin{array}{l}\text { Evidence of } \\
\text { ascending }\end{array}$ & $\begin{array}{l}\text { Evidence of } \\
\text { ascending }\end{array}$ & $\begin{array}{l}\text { Evidence of } \\
\text { ascending }\end{array}$ & $\begin{array}{l}\text { Evidence of } \\
\text { ascending }\end{array}$ \\
\hline intrauterine & intrauterine & intrauterine & intrauterine \\
\hline infection & infection & infection & infection \\
\hline $\begin{array}{l}\text { Maternal inflammatory } \\
\text { response }\end{array}$ & $2(3.8)$ & $4(4.7)$ & 0.128 \\
\hline $\begin{array}{l}\text { Fetal inflammatory } \\
\text { response }\end{array}$ & $2(3.8)$ & $2(6.3)$ & 0.601 \\
\hline Ascending intrauterine & $3(5.7)$ & $5(15.6)$ & 0.127 \\
\hline
\end{tabular}




\begin{tabular}{|c|c|c|c|}
\hline Placental Lesion & $\begin{array}{l}\text { High CVD Risk }(\mathrm{n}= \\
\text { 53) }\end{array}$ & $\begin{array}{l}\text { Low CVD Risk }(n= \\
32)\end{array}$ & $P$-value $\left(\right.$ Pearson $\left.X^{2}\right)$ \\
\hline Evidence of & Evidence of & Evidence of & Evidence of \\
\hline $\begin{array}{l}\text { placenta villous } \\
\text { maldevelopment }\end{array}$ & $\begin{array}{l}\text { placenta villous } \\
\text { maldevelopment }\end{array}$ & $\begin{array}{l}\text { placenta villous } \\
\text { maldevelopment }\end{array}$ & $\begin{array}{l}\text { placenta villous } \\
\text { maldevelopment }\end{array}$ \\
\hline Chorangiosis & $0(0)$ & $0(0)$ & - \\
\hline Chorangiomas & $0(0)$ & $0(0)$ & - \\
\hline $\begin{array}{l}\text { Delayed villous } \\
\text { maturation }\end{array}$ & $1(1.9)$ & $2(6.3)$ & 0.291 \\
\hline $\begin{array}{l}\text { Evidence of fetal } \\
\text { vascular } \\
\text { malperfusion }\end{array}$ & $\begin{array}{l}\text { Evidence of fetal } \\
\text { vascular } \\
\text { malperfusion }\end{array}$ & $\begin{array}{l}\text { Evidence of fetal } \\
\text { vascular } \\
\text { malperfusion }\end{array}$ & $\begin{array}{l}\text { Evidence of fetal } \\
\text { vascular }\end{array}$ \\
\hline Avascular fibrotic villi & $2(3.8)$ & $0(0)$ & 0.266 \\
\hline Thrombosis & $1(1.9)$ & $1(3.1)$ & 0.715 \\
\hline $\begin{array}{l}\text { Intramural fibrin } \\
\text { deposition }\end{array}$ & $0(0)$ & $3(9.4)$ & 0.023 \\
\hline Karyorrhexis & $0(0)$ & $0(0)$ & - \\
\hline $\begin{array}{l}\text { High-grade fetal } \\
\text { vascular malperfusion }\end{array}$ & $2(3.8)$ & $0(0)$ & 0.266 \\
\hline $\begin{array}{l}\text { Fetal vascular } \\
\text { malperfusion present }\end{array}$ & $4(7.5)$ & $5(15.6)$ & 0.241 \\
\hline Fibrinoid & Fibrinoid & Fibrinoid & Fibrinoid \\
\hline $\begin{array}{l}\text { Increased focal } \\
\text { perivillous fibrin } \\
\text { deposition }\end{array}$ & $2(3.8)$ & $2(6.3)$ & 0.601 \\
\hline $\begin{array}{l}\text { Massive Perivillous } \\
\text { fibrin deposition } \\
\text { pattern }\end{array}$ & $1(1.9)$ & $0(0)$ & 0.434 \\
\hline $\begin{array}{l}\text { Maternal floor } \\
\text { infarction pattern }\end{array}$ & $0(0)$ & $0(0)$ & - \\
\hline Intervillous thrombi & Intervillous thrombi & Intervillous thrombi & Intervillous thrombi \\
\hline Intervillous thrombi & $5(9.4)$ & $1(3.1)$ & 0.271 \\
\hline $\begin{array}{l}\text { Evidence of chronic } \\
\text { inflammation }\end{array}$ & $\begin{array}{l}\text { Evidence of chronic } \\
\text { inflammation }\end{array}$ & $\begin{array}{l}\text { Evidence of chronic } \\
\text { inflammation }\end{array}$ & $\begin{array}{l}\text { Evidence of chronic } \\
\text { inflammation }\end{array}$ \\
\hline $\begin{array}{l}\text { Villitis of unknown } \\
\text { etiology }\end{array}$ & $5(9.4)$ & $3(9.4)$ & 0.993 \\
\hline Chronic intervillositis & $0(0)$ & $0(0)$ & - \\
\hline $\begin{array}{l}\text { Chronic plasma cell } \\
\text { deciduitis }\end{array}$ & $5(9.4)$ & $3(9.4)$ & 0.993 \\
\hline $\begin{array}{l}\text { Chronic inflammation } \\
\text { present }\end{array}$ & $7(13.2)$ & $6(18.8)$ & 0.492 \\
\hline
\end{tabular}

MVM: maternal vascular malperfusion

\section{Hosted file}

Figure_1.docx available at https://authorea.com/users/431480/articles/534974-association-ofplacental-pathology-and-postpartum-cardiovascular-risk-screening-following-preeclampsiaan-observational-cohort-study 